\title{
PENGARUH MUSEUM EXPERIENCE TERHADAP KEPUTUSAN BERKUNJUNG (Survei Pada Wisatawan Nusantara Yang Berkunjung di Museum Kereta Api Ambarawa)
}

\author{
Elsa Dwi Melyanti \\ Rini Andari \\ Oce Ridwanudin
}

Manajemen Pemasaran Pariwisata FPIPS UPI

\begin{abstract}
Indonesia has a lot of economic potential, especially in tourism. Tourism has a definition as a people activity which travelling from one place to another, stay outside their ordinary environtment no more than one year to relax, leisure and another activity which not related to work. In order to run tourism activity properly, it require supporting facilities such as tourist attraction, hotels, restaurants, and travel agent. Semarang is the city with a high activity tourism activity, it seen from much variety of tourist attraction. And the most interesting tourist attraction in Semarang is museum. Museum Kereta Api Ambarawa is the most visited museum by the tourist, it has strategic location and has very complete and diverse museum collections. Museum Kereta Api Ambarawa implement museum experience strategy to increase tourists arrival. The purpose of this research was to look for the findings in museum experience implementation, decision to visit and the impact of museum experience to tourist decision. Object in this research is domestic tourists who visiting Museum Kereta Api Ambarawa. The type of research is descriptive and verification, and this research used explanatory survey method, with systematic random sampling technique, with the samples of 1000 respondents. Data analysis technique used multiple linear regression with SPSS 20 for windows software as a tools. Data collecting technique using interviews and surveys. The research findings that museum experience with Recreation (X1), Sociability (X2), Learning Experience (X3), Celebrate Experience (X4) dimention has an impact to tourist travelling decision which consisting of product selection, brand selection, distribution channel selection, visiting time decision, and payment method used.
\end{abstract}

Keywords: museum experience, the decision of a visit

\section{PENDAHULUAN}

\subsection{Latar Belakang Penelitian}

Pertumbuhuan pariwisata saat ini merupakan bentuk nyata dari perjalanan sebuah bisnis global yang memang sangat menjanjikan karena pertumbuhan pariwisata itu sendiri mampu mendorong pertumbuhan ekonomi dunia yang dihasilkan dari pergerakan wisatawannya. Jawa Tengah merupakan salah satu provinsi yang industri pariwisatanya tengah mengalami perkembangan Salah satu potensi wisata yang ditawarkan adalah banyaknya museum yang menjadi bukti warisan budaya yang telah ada dari zaman dahulu. Museum Kereta Api Ambarawa merupakan sebuah museum terbuka yang dahulu adalah sebuah stasiun kereta api pada masa penjajahan Belanda.

Tabel dibawah dapat terlihat bahwa adanya kenaikan jumlah pengunjung yang sangat pesat pada tahun 2008 sampai dengan tahun 2011, dan terjadi penurunan pada tahun 2012 hal ini disebabkan karena banyaknya destinasi wisata yang dibangun baik oleh pihak swasta, maupun dari pemerintah. Adanya destinasi baru yang lebih atraktif, lebih menyajikan nuansa yang lebih menarik dan lebih memberikan pengalaman yang baik di benak wisatawaan

TABEL 1.1

\section{JUMLAH KUNJUNGAN WISATAWAN} DI MUSEUM KERETA API

AMBARAWA TAHUN 2008-2012

\begin{tabular}{|c|c|}
\hline Tahun & Jumlah \\
\hline 2009 & 48.231 \\
\hline 2010 & 50.874 \\
\hline 2011 & 53.413 \\
\hline 2012 & 51.276 \\
\hline
\end{tabular}

Sumber: Museum Kereta Api Ambarawa (2012)

Program yang dapat meningkatkan jumlah kunjungan di museum kereta api Ambarawa dapat dilihat pada Tabel 1.2 berikut : 
TABEL 1.2

MUSEUM EXPERIENCE KERETA API AMBARAWA

\begin{tabular}{|c|c|}
\hline $\begin{array}{l}\text { MUSEUM } \\
\text { EXPERIENCE }\end{array}$ & KETERANGAN \\
\hline Recreation & 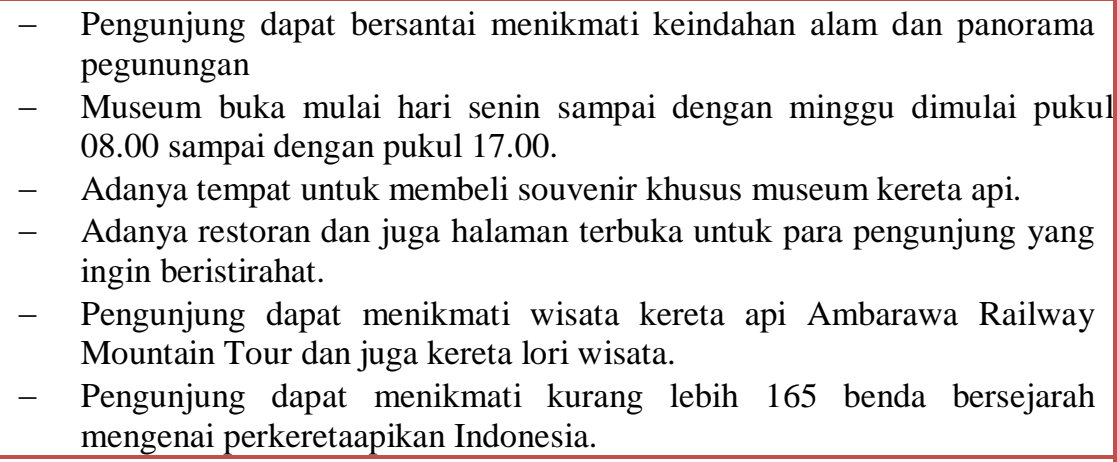 \\
\hline Sociability & $\begin{array}{ll}\text { - } & \text { Dapat mengunjungi pameran secara berkelompok. } \\
\text { - } & \text { Tersedianya restoran yang bertujuan untuk tempat beristirahat } \\
\text { wisatawan atau sekedar untuk makan siang bersama teman atau klien. } \\
\text { - } \quad \text { Adanya Tanya jawab bersama para wisatawan dan juga tour guide } \\
\text { tantang sejarah perkeretaapian Indonesia. }\end{array}$ \\
\hline $\begin{array}{l}\text { Learning } \\
\text { experience }\end{array}$ & $\begin{array}{l}\text { - Adanya ruang pameran yang memamerkan barang peninggalan sejarah } \\
\text { tentang perkeretaapian Indonesia. } \\
\text { - Disediakanya pemandu atau tour guide yang dapat menjelaskan seluruh } \\
\text { produk yang ada di dalam museum Kereta Api Ambarawa. }\end{array}$ \\
\hline $\begin{array}{l}\text { Celebrative } \\
\text { experience }\end{array}$ & $\begin{array}{l}\text { - Pengunjung dapat merasakan sensasi menaiki kereta uap bergerigi } \\
\text { sejauh } 35 \mathrm{Km} \text { dan menikmati keindahan alam pegunungan. }\end{array}$ \\
\hline
\end{tabular}

Sumber: Museum Kereta Api Ambarawa 2012

Melalui program museum experience diharapkan dapat menarik wisatawan untuk kembali mengunjungi museum dan juga dapat menaikan jumlah kunjungan wisatawan yang menurun karena adanya destinasi baru yang lebih atraktif, lebih menyajikan nuansa yang lebih menarik dan lebih memberikan pengalaman yang baik di benak wisatawaan.

\subsection{Rumusan Masalah}

Berdasarkan latar belakang penelitian yang telah diungkapkan, maka dapat dirumuskan masalah penelitian adalah sebagai berikut

1. Bagaimana gambaran mengenai museum experience di Museum Kereta Api Ambarawa?

2. Bagaimana keputusan berkunjung di Museum Kereta Api Ambarawa?

3. Seberapa besar pengaruh museum experience terhadap keputusan berkunjung di Museum Kereta Api Ambarawa?

\subsection{Tujuan Penelitian}

Adapun tujuan penelitian ini untuk memperoleh hasil temuan mengenai
1. Gambaran museum experience di Museum Kereta Api Ambarawa.

2. Keputusan berkunjung di Museum Kereta Api Ambarawa.

3. Pengaruh museum experience terhadap keputusan berkunjung di museum Kereta Api Ambarawa

\section{KAJIAN PUSTAKA}

\subsection{Museum Experience}

Menurut Kotler dan Nail (2008:5)

Beberapa dari wisatawan mencari kesenangan yang mana mereka dapat terlibat langsung dalam sebuah pengalaman yang didalamnya terdapat unsur edukasi, kesempatan untuk berekreasi, belajar, melihat pameran, mencari tempat untuk bersantai dan sekedar untuk membeli souvenir dan juga makanan.

\subsubsection{Sociability}

Meliputi pertemuan dengan atau berpartisipasi dengan orang lain, melihat bersama-sama dengan orang lain, mengambil bagian dalam berbagi, kegiatan umum. 


\subsubsection{Recreation}

Meliputi kenikmatan bebas, santai, terstruktur waktu, kegiatan yang menyenangkan dan pengalihan kegiatan. kegiatan yang dapat menyegarkan tubuh dan jiwa.

\subsubsection{Learning Experience}

Kegiatan learning experience meliputi mengumpulkan dan memperoleh informasi baru, menyerap pola, berolahraga, rasa ingin tahu dan rasa penemuan, pemahaman konsep dan pemikiran, merenungkan dan reflecting, berlatih kemampuan kognitif.

\subsubsection{Aesthetic experience}

Terlibat dalam kualitas pengalaman yang melekat dalam nuansa itu sendiri melalui indera kita, terlibat dalam intensif fokus kegiatan.

\subsubsection{Celebrative Experience}

Mengamati dan menghormati pemimpin, peristiwa, kelompok, atau organisasi, berbagi dalam prestasi, menghubungkan dengan masa lalu, catatan sejarah, kelangsungan melalui sejarah dan waktu, menghadapi standar yang refine sensibilitas, memperbesar fikiran, dan bentuk aspirasi.

\subsubsection{Issue - oriented experience :}

Menghadapi dan terlibat dalam isu publik yang kontemporer yang dapat mempengaruhi sebuah dan kepedulian masyarakat setempat serta masyarakat yang lebih besar.

\subsection{Keputusan Berkunjung

Kotler \& Keller
menyebutkan terdapat enam dimensi dari keputusan berkunjung diantaranya: Pilihan produk, Pilihan merek, Pilihan Saluran pembelian, Penentuan Waktu Pembelian, Jumlah Pembelian, dan Metode Pembayaran

1. Pilihan produk/jasa

Wisatawan dapat mengambil keputusan untuk mengunjungi sebuah kawasan wisata untuk tujuan yang lain.

2. Pilihan brand (merek)

Wisatawan harus dapat memutuskan kawasan wisata yang akan dikunjungi. Setiap kawasan wisata memiliki perbedaan tersendiri.

3. Pilihan dealer

Wisatawan memiliki perbedaan dalam hal menentukan dealer mana yang akan digunakan yang disebabkan faktor lokasi, harga yang murah, persediaan barang lengkap, kenyamanan berbelanja, keluasan tempat dan sebagainya.

4. Waktu kunjungan

Keputusan wisatawan untuk berkunjung bisa berbeda sesuai dengan kebutuhan wisatawan. Waktu kunjungan menentukan masa puncak dan sepi selama setahun kedatangan dan keberankatan wisatawan.

5. Jumlah kunjungan

Wisatwan dapat mengambil keputusan tentang seberapa banyak produk/jasa wisata yang akan dikunjungi. Kunjungan dilakukan mungkin lebih dari satu.

6. Metode pembayaran

Wisatawan dalam mengunjungi suatu kawasan wisata pasti harus melakukan suatu pembayaran. Pada saat pembayaran inilah biasanya wisatawan ada yang melakukan pembayaran secara tunai maupun menggunakan kartu kredit.

\section{III.METODE PENELITIAN}

\subsection{Objek Penelitian}

Penelitian ini dilakukan untuk menganalisis mengenai strategi museum experience di museum kereta api Ambarawa untuk meningkatkan keputusan berkunjung wisatawan. Adapun yang menjadi objek penelitian sebagai variabel bebas adalah museum experience (X) yang memiliki empat sub variabel, recreation $\left(\mathrm{X}_{1}\right)$, sociabillity $\left(\mathrm{X}_{2}\right)$ learning experience $\left(\mathrm{X}_{3}\right)$ dan celebrative experience (X4). Sedangkan untuk variabel terikat atau (Y) adalah keputusan berkunjung.

\subsection{Jenis dan Metode Penelitian}

Berdasarkan tujuan penelitian dan variabel-variabel yang diteliti, maka jenis penelitian ini adalah penelitian deskriptif dan verifikatif, yaitu menguji kebenaran suatu hipotesis yang telah diuraikan pada Bab II, melalui pengumpulan data di lapangan (wisatawan nusantara yang berkunjung di Museum Kereta Api Ambarawa)

\subsection{Populasi dan sampel}

Dalam menentukan ukuran sampel (n) dan populasi (N) yang telah ditetapkan, maka dalam penelitian ini menggunakan rumus Slovin (Husein Umar, 2008:59) yaitu sebagai berikut:

Rumus :

$$
\mathrm{n}=\frac{N}{1+N \mathrm{e}^{2}}
$$


Keterangan

$\mathrm{n}=$ Ukuran Sampel

$\mathrm{N}=$ Ukuran Populasi

e = Kelonggaran ketidaktelitian karena

kesalahan sampel yang dapat ditolerir

\subsection{Teknik Sampling}

Teknik sampling adalah teknik pengambilan sampel. Untuk menentukan sampel yang akan digunakan dalam penelitian terdapat berbagai teknik sampling yang digunakan dalam penelitian ini salah satunya adalah teknik systematic random sampling atau teknik pengambilan sampel acak sistematis untuk populasi yang bergerak.

\subsection{Pengujian Hipotesis}

Teknik analisis data yang digunakan dalam penelitian ini adalah regresi linear berganda (multiple linear regression). Analisis regresi linear berganda adalah suatu alat analisis peramalan nilai pengaruh dua atau lebih variabel bebas (X) terhadap variabel terikat (Y) untuk membuktikan ada atau tidaknya hubungan kausal antara dua variabel bebas atau lebih. Untuk bisa membuat ramalan melalui regresi, maka data setiap variabel harus tersedia. Berdasarkan data tersebut peneliti harus menemukan persamaan regresi berganda melalui perhitungan sebagai berikut:

$\mathrm{Y}=\mathrm{a}+\mathrm{bX} 1.1+\mathrm{bX} 1.2+\mathrm{bX} 1.3+\mathrm{bX} 1.4$

Keterangan:

$\mathrm{Y}=$ Subyek dalam variabel dependen yang diprediksikan

$\mathrm{a}=$ Harga $\mathrm{Y}$ bila $\mathrm{X}=0$

$\mathrm{b}=$ Angka arah atau koefisien regresi, yang menunjukan angka peningkatan ataupun penurunan variabel dependen yang didasarkan pada variabel independen. Bila b (+) maka naik, dan bila (-) maka terjadi penurunan.

$\mathrm{X}=$ Subyek pada variabel independen yang mempunyai nilai tertentu. X1, X2, X3, $\mathrm{X} 4,=$ variabel penyebab $(\mathrm{X} 1=$ Recreation $),(\mathrm{X} 2=$ Sociabillity $),(\mathrm{X} 3=$ Learning Experience), (X4 = Celebrative Experience).

Analisis regresi berganda akan dilakukan bila jumlah variabel independen minimal dua atau lebih. Menerjemahkan ke dalam beberapa sub hipotesis yang menyatakan pengaruh sub variabel independen yang paling dominan terhadap variabel dependen, lebih jelasnya dapat dilihat pada Gambar 3.1 berikut:

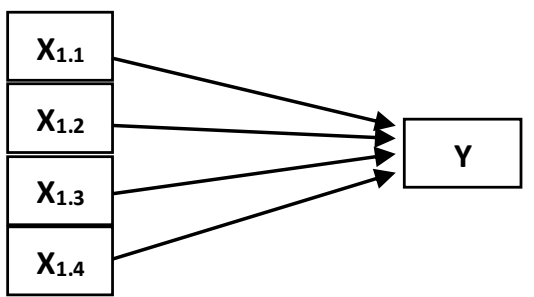

GAMBAR 3.1

REGRESI BERGANDA

Keterangan :

$\mathrm{X}_{1.1} \quad=$ Recreation

$\mathrm{X}_{1.2}=$ Sociabillity

$\mathrm{X}_{1.3} \quad=$ Learning Experience

$\mathrm{X}_{1.4}=$ Celebrative Experience

$\mathrm{Y}=$ Keputusan berkunjung

Uji Hipotesis regresi berganda digunakan untuk menguji signifikan atau tidaknya hubungan lebih dari dua variabel melalui koefisien regresinya. Uji hipotesis pada penelitian ini dilakukan secara simultan dan parsial.

\section{IV.HASIL PENELITIAN DAN} PEMBAHASAN

4.1 Hasil Uji Asumsi Variabel

4.1.1 Pengujian Asumsi Regresi

a) Hasil Uji Asumsi Normalitas

Syarat pertama untuk melakukan analisis regresi adalah normalitas, sebagaimana yang diungkapkan oleh Triton (2005:76) bahwa data sampel hendaknya memenuhi prasyarat distribusi normal yaitu data yang akan dianalisis dengan statistic parametric harus mengikuti distribusi normal

Histogram

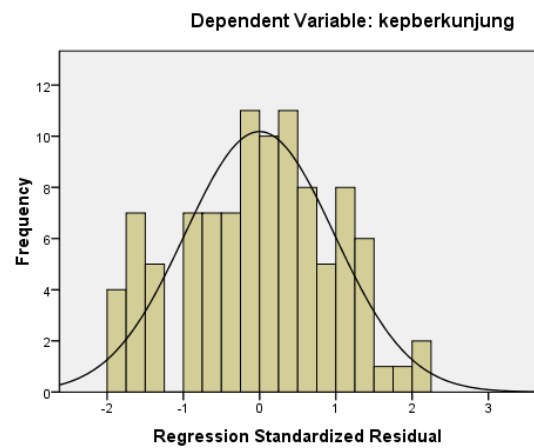

Sumber: Hasil Pengolahan Data Primer, 2014

GAMBAR 4.1 HISTOGRAM DEPENDENT VARIABEL 
Gambar 4.1 dapat dikatakan bahwa model berdistribusi normal karena kurva membetuk lonceng. Pengujian ini dilakukan dengan menggunakan normal probability plot.Gambar 4.2 berikut ini menggambarkan normal probability plot yang digunakan untuk mendeteksi apakah data yang digunakan berdistribusi normal atau tidak.
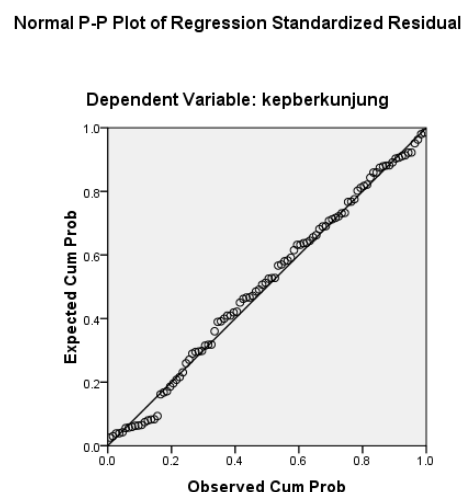

Sumber: Hasil Pengolahan Data Primer, 2014

GAMBAR 4.2

\section{NORMAL PROBABILITY PLOT}

Suatu model regresi layak dipakai apabila nilai residunya mengikuti distribusi normal atau pada Gambar 4.2 nilai residu berdistribusi normal apabila sebaran datanya terletak disekitar garis diagonal dan mengikuti arah diagonal yaitu dari kiri bawah ke kanan atas.

b) Hasil Uji Asumsi

Heteroskedastisitas

Heteroskedastisitas adalah varian residual yang tidak konstan pada regresi sehingga akurasi hasil prediksi menjadi menyebar. Residu pada heteroskedastisitas semakin besar apabila pengamatan semakin besar. Suatu regresi dikatakan tidak terdeteksi heteroskedastisitas apabila penyebaran terhadap harga-harga prediksi tidak membentuk suatu pola tertentu (meningkat atau menurun).

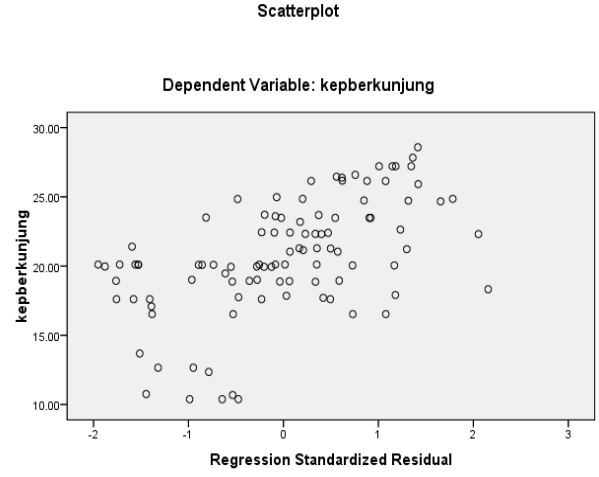

Sumber: Hasil Pengolahan Data Primer, 2014.

\section{GAMBAR 4.3 \\ UJI HETEROSKEDASTISITAS}

Berdasarkan Gambar 4.3 maka dapat dilihat bahwa sebaran data terdapat disekitar titik nol dan tidak tampak adanya suatu pola tertentu pada sebaran data tersebut. Dengan demikian data yang akan dianalisis memenuhi asumsi heteroskedastisita.

\section{c) Pengujian Multikolinieritas}

Multikolinearitas artinya terdapat hubungan linear yang sempurna atau pasti diantara beberapa atau semua variabel yang menjelaskan dari model regresi, yaitu terdapatnya lebih dari satu hubungan linear pasti

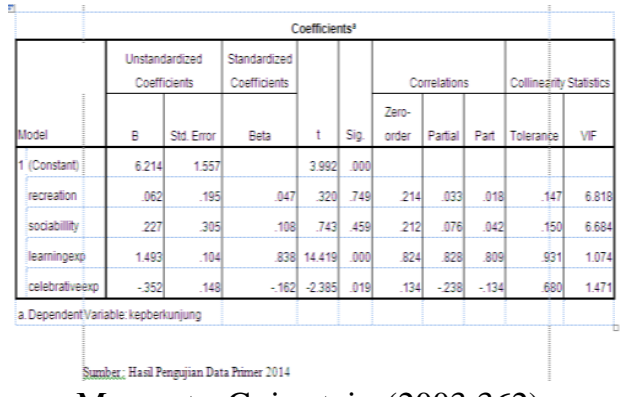

Menurut Gujaratai (2003:362) cara untuk melihat adanya multikolinearitas atau tidak adalah dengan melihat apakah nilai VIF untuk masing-masing variabel lebih besar dari 10 atau tidak. Bila nilai VIF lebih besar dari 10 maka diindikasikan bahwa model tersebut memiliki gejala multikolinearitas. Berdasarkan tabel 4.15 bahwa seluruh variabel memiliki nilai VIF kurang dari 10 maka dapat disimpulkan bahwa penelitian ini tidak memiliki gejala multikolinearitas. 


\subsubsection{Koefisien Korelasi dan Koefisien Determinasi}

Untuk mengetahui seberapa kuat hubungan dan seberapa besar pengaruh Museum Experience dapat dilihat melalui nilai koefisien korelasi dan determinasi.

TABEL 4.1

OUTPUT PENGARUH MUSEUM EXPERIENCE TERHADARP KEPUTUSAN BERKUNJUNG MUSEUM KERETA API AMBARAWA

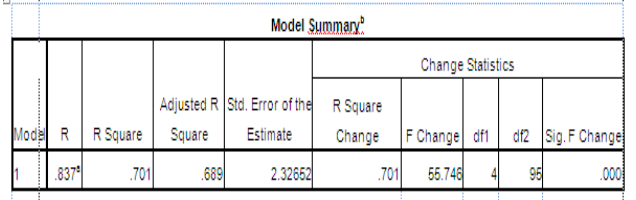

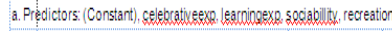

b. Dependent Variable: Keoberlyniun

Sumber : Hasil Pengujian Data Primer 2014

Tabel 4.1 diperoleh nilai koefisien korelasi museum experience dengan keputusan berkunjung sebesar 0,837. Bila korelasi tersebut diinterpretasikan pada tabel korelasi maka hubungan antara museum experience terhadap keputusan berkunjung memiliki hubungan yang kuat sesuai dengan klasifikasi koefisien korelasi menurut Sugiyono (2010:250). Berdasarkan hasil perhitungan, nilai koefesien determinasi adalah 0,689 atau $68,9 \%$. hal ini menunjukan bahwa secara bersama-sama variabel museum experience memberikan kontribusi sebesar $68,9 \%$. terhadap keputusan berkunjung .

\subsubsection{Pengujian ANOVA (Uji F)}

Untuk menguji signifikasi dapat digunakan uji $\mathrm{F}$, berikut ini tabel mengenai output ANOVA

TABEL 4.2

OUTPUT TABEL ANNOVA

\begin{tabular}{|c|c|c|c|c|c|c|}
\hline \multicolumn{7}{|c|}{ ANOVA } \\
\hline & & Sum of Squares & df & Mean Square & $F$ & Sig. \\
\hline \multirow[t]{3}{*}{1} & Regression & 1206.938 & 4 & 301.735 & 55.746 & $.000^{\circ}$ \\
\hline & Residual & 514.207 & 95 & 5.413 & & \\
\hline & Total & 1721.146 & 99 & & & \\
\hline
\end{tabular}

a. Predictors: (Constant), celebratitueexp leaccoingexx, sociability, recreation b. Dependent Variable: kepberkuniung

Tabel 4.2 diatas, diperoleh nilai $F_{\text {hitung }}$ $=55.746$ sedangkan $F_{\text {tabel }}$ dengan derajat kebebasan pada $\alpha(0.05)$ adalah sebesar 1,02 dengan nilai signifikansinya 0,000 . Nilai signifikansi lebih kecil dari taraf signifikansi 5\%, sehingga Ho ditolak dan $\mathrm{Hi}$ diterima. Dengan nilai signifikansi 0,000 nilai signifikansi lebih kecil dari taraf signifikansi
5\% maka regresi dapat digunakan untuk memprediksi keputusan berkunjung wisatawan atau variabel museum experience berpengaruh terhadap keputusan berkunjung wisatawan di museum kereta api Ambarawa.

\subsubsection{Pengujian Hipotesis dan Signifikansi Secara Parsial (Uji t)}

Pengujian ini digunakan untuk mengetahui pengaruh sub-variabel mana yang paling dominan dari keseluruhan variabel bebas museum experience yang terdiri dari Recreation, Sociabillity, Learning experience, celebrative experience. Regresi sebuah variabel mempunyai pengaruh yang berarti terhadap perubahan nilai $\mathrm{Y}$ jka nilai $\mathrm{t}$ hitung $>\mathrm{t}$ tabel . Berikut penyajian hasil analisis dalam Tabel 4.19 berikut ini

TABEL 4.3

OUTPUT ANALISIS KOEFISIEN REGRESI

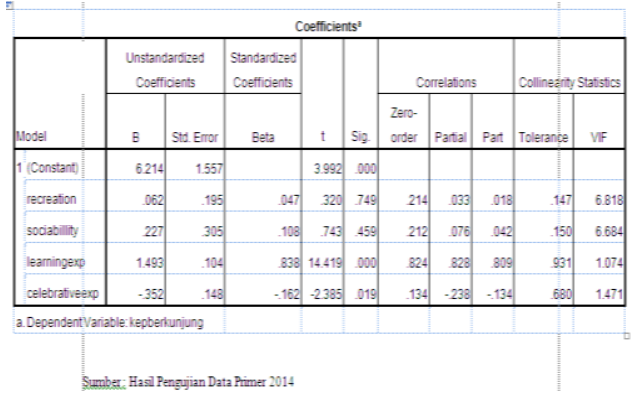

Sumber: Hasil Pengujian 2014

Tabel 4.3 secara parsial menunjukkan bahwa tidak semua sub variabel bebas museum experience memiliki signifikasi kurang dari 0,05 , artinya sub variabel tidak berpengaruh terhadap keputusan berkunjung atau Ho diterima.

Hasil analisis menunjukkan terdapat dua variabel bebas yang memiliki signifikan kurang dari 0,05 yaitu learning experience dan celebrative experience yang artinya sub variabel ini berpengaruh terhadap keputusan berkunjung dan Ho ditolak. Pada penelitian ini secara parsial disimpulkan bahwa :

1. Sig.t $=0,749>0.05$, maka tidak terdapat pengaruh yang signifikan dari recreation terhadap keputusan berkunjung di museum kereta api Ambarawa.

2. $\operatorname{Sig} \mathrm{t}=0,459>0,05$, maka tidak terdapat pengaruh yang signifikan dari sociabillity terhadap keputusan berkunjung di museum kereta api Ambarawa 
3. Sig $\mathrm{t}=0,00<0,05$, maka terdapat pengaruh yang signifikan dari learning experience terhadap keputusan berkunjung di museum kereta api Ambarawa.

4. Sig $\mathrm{t}=0,019<0,05$, maka terdapat pengaruh yang signifikan dari celebrative experience terhadap keputusan berkunjung di museum kereta api Ambarawa.

Berdasarkan hasil pengujian diatas dari empat sub-variabel yang diuji secara parsial hanya dua yang memiliki pengaruh positif terhadap keputusan berkunjung wisatawan di museum kereta api Ambarawa yaitu sub dimensi learning experience yang merupakan kejelasan, kepahaman wisatawan terhadap produk yang ada di dalam museum sedangkan sub dimensi celebrative experience merupakan rasa hormat wisatawan terhadap kreatifitas yang dilakukan oleh manusia pada jaman dahulu.

\subsubsection{Model Persamaan Regresi Pengaruh Museum Experience Terhadap Keputusan Berkunjung Di Museum Kereta Api Ambarawa}

Berdasarkan hasil pengolahan data maka dihasilkan persamaan regresi sebagai berikut:

$$
\mathrm{Y}=6,214+1,493(\mathrm{X} 1.3)+-0,352(\mathrm{X} 1.4)
$$

Keterangan :

$\mathrm{Y}=$ Keputusan berkunjung

$\mathrm{X} 1.3$ = learning experience

$\mathrm{X} 1.4=$ Celebrative experience

Berdasarkan persamaan di atas, maka nilai koefisien regresi dapat dijelaskan sebagai berikut:

1. learning experience $(\mathrm{X} 1.3)=1,493$ maka perubahan favorability sebesar satu satuan maka akan menimbulkan kontribusi sebesar 6,214 +1,493 (1) = 7,707 terhadap keputusan berkunjung.

2. Celebrative experience $(\mathrm{X} 1.4)=-0,837$ maka perubahan favorability sebesar satu satuan maka akan menimbulkan kontribusi sebesar 6,214 +-0,352 (1) = 5,862 terhadap keputusan berkunjung

\section{KESIMPULAN DAN SARAN}

Museum experience melalui subvariabel Recreation perlu untuk memperhatikan beragam kegiatan yang ada di museum seperti berwisata mengelilingi museum, wahana kereta uap, kereta bergerigi, kereta wisata dan juga kegiatan wisata berbelanja souvenir

Sub-variabel Sociabillity memiliki skor terendah perlu diperhatikan pihak museum seharusnya menggunakan pemandu wisata yang sudah professional supaya dapat mengajak wisatawan masuk secara mendalam kedalam cerita catatan sejarah masa lalu tentang perkeretaapian Indonesia,

Sub-variabel learning experience harus dapat memberikan informasi yang lengkap kepada wisatawan dengan cara memberika brosur atau buku panduan kepada wisatawan supaya wisatawan tidak kebingungan dalam mencari dan mendapatkan informasi mengenai museum.

Sub-Variabel celebrative experience harus merawat dan memelihara produknya agar tetap terawat dengan harapan agar wisatawan bisa merasa bangga dan terbawa ke kehidupan di masa lalu dengan melihat produk yang ditawarkan di museum.

keputusan berkunjung di museum kereta api Ambarawa harus senantiasa mempertahankan dan meningkatkan mutu produknya untuk mempertahankan tingkat keputusan berkunjung.

\section{DAFTAR PUSTAKA}

, Garry Amstrong. (2012). Principles of marketing 14th. New Jersey: Pearson Prentice Hall. , Kevin Lane Keller. (2012). Marketing Management 14th. New Jersey: Pearson Prentice Hall.

(2012). Metode Penelitian Kuantitatif Kualitatif dan $R \& D$. Bandung: CV ALFABETA.

Amenta Carlo, (2010), exploring museum marketing performance, international journal of marketing studies

Buchari Alma. (2007), Manajemen Pemasaran Dan Pemasaran Jasa, Bandung: Alfabeta Bandung

Chieh-Wen Sheng, Ming-Chia Chen. (2012). A study of experience expectations of museum visitor. Elseiver

Eva reussner. 2005. museum marketing research. Bowater school of management and marketing Deakin University 
Ginsburgh dan mairesse. (2009). Issues in the international market for cultural heritage, economics of cultural heritage

Goulding Christina. (2010). Museum visitors experiences. Emerald

Kerin dan Paterson. (2007). Strategic Marketing Problems. $12^{\text {th }}$ Edition. Nick book house

Kotler Philip. Neil G. Wendy. (2008). Museum and Marketing Strategy Second edition. Jossey-Bass.

L. Kesner. (2006). The role of cognitive competence in the art museum experience. Elseiver

Pitana, I. Gede dan Gayatri, Putu G (2005). Sosiologi Pariwisata. Yogyakarta: Andi.

Schiffman dan Kanuk (2007). Consumer behavior. New jersey: Perason prestice hall

Sugiyono. (2010). Metode Penelitian Bisnis. Bandung: CV ALFABETA

Suharsimi, Arikunto. (2009). Prosedur Penelitian Suatu Pendekatan Praktis. Yogyakarta: Bina Aksara.

Uma Sekaran. (2006). Research Methods For Business. Jakarta: Salemba Empat. 